\title{
HUBUNGAN DISIPLIN BELAJAR DENGAN HASIL BELAJAR SISWA PADA MATA PELAJARAN MATEMATIKA KELAS V DI SD NEGERI 24 TANJUNG BUNGA
}

\author{
Devi Efa Naibaho, Regina Sipayung, Darinda Sofia Tanjung \\ Surel: deviefa1998@gmail.com
}

\begin{abstract}
This study aims to determine the level of learning discipline at SD Negeri 24 Tanjung Bunga and its relationship with students learning outcomes. The sample in the study consisted of 32 students. The method of research used is descriptive-correlational. The instrument used to measure the discipline of study was a questionnaire which consisted of 30 items. Meanwhile, the value of the results of the report cards semester of even years of teachings in 2020 was used to measure the outcomes of learning. The results obtained that the value of the mean (average) score of the questionnaire amounted was 120,5. It means that the students studying discipline at SD Negeri 24 Tanjung Bunga are at a higher level. To determine the level of relationship between the disciplinary study with the results of the study, the formula of the Pearson correlation wasapplied. From the calculation results, $r$ was 0.752 , which means that the correlation value is strong/correlated. Test of significance was applied to test the hypothesis by comparing the value of $t$ arithmetic with $t$ table. It was obtained that the value of $t=6.248$ while the table $=1.697$. Because $t$ count $\geq t$ table (6,248 $\geq 1,697), H_{o}$ was accepted and $H_{a}$ was rejected. Throught test, it can be concluded that there is a significant relationship between thestudentslearning discipline and students learning outcomes.
\end{abstract}

Keywords: Relationship, Students Learning Discipline, Students Learning Outcomes

\begin{abstract}
ABSTRAK
Penelitian ini bertujuan untuk mengetahui tingkat disiplin belajar siswa di SD Negeri 24 Tanjung Bunga serta hubungannya dengan hasil belajar. Sampel dalam penelitian terdiri dari 32 siswa. Metode penelitian yang digunakan adalah deskriptif-korelasional. Instrument yang digunakan untuk mengukur disiplin belajar adalah angket yang terdiri dari 30 butir. Sedangkan untuk mengukur hasil belajar digunakan nilai hasil raport semester genap tahun ajaran 2020. Untuk mengetahui tingkat hubungan antara disiplin belajar dengan hasil belajar digunakan rumus korelasi dari Pearson. Dari hasil perhitungan diperoleh $\mathrm{r}_{\text {hitung }} 0,752$, yang berarti nilai korelasi kuat/berkorelasi. Uji signifikasi dilakukan untuk menguji hipotesis, yaitu dengan membandingkan nilai $t_{\text {hitung }}$ dengan $t_{\text {tabel. }}$. Diperoleh nilai $t_{\text {hitung }}=6,248$ sedangkan $t_{\text {tabel }}=1,697$. Karena $t_{\text {hitung }} \geq t_{\text {tabel }}(6,248 \geq 1,697)$ maka $H_{o}$ diterima dan $\mathrm{H}_{\mathrm{a}}$ ditolak. Melalui uji $\mathrm{t}$ tersebut dapat disimpulkan bahwa terdapat hubungan yang signifikan antara disiplin belajar siswa dengan hasil belajarnya.
\end{abstract}

Kata Kunci : Hubungan, Disiplin Belajar Siswa, Hasil Belajar Siswa. 



\section{PENDAHULUAN}

Pendidikan merupakan salah satu hal utama dalam kehidupan manusia khususnya berbangsa dan bernegara. Pendidikan adalah salah satu usaha sadar dalam menciptakan sumber daya manusia yang berkualitas dan mewujudkan suasana belajar dan proses pembelajaran untuk peserta didik secara aktif mengembangkan potensi dirinya untuk memiliki pengendalian diri, kepribadian, kecerdasan, akhlak mulia, serta taraf hidup untuk kemajuan lebih baik. Disiplin merupakan salah satu syarat mutlak kesuksesan untuk mencapai cita-cita dalam dunia pendidikan. Dalam dunia pendidikan disiplin sekolah sangatlah penting. Disiplin dapat membantu siswa untuk belajar lebih giat dan rajin.

Berdasarkan observasi awal yang dilakukan peneliti di SD Negeri 24 Tanjung Bunga, bahwa siswa di sekolah tersebut masih ada anak yang tidak serius mengikuti pembelajaran. Siswa tidak memperhatikan guru saat mengajar, siswa yang masih menggangu temannya, siswa yang bermain sendiri, siswa yang mengantuk pada saat pembelajaran, dan rasa ingin tahu siswa akan pembelajaran tersebut masih rendah. Hal ini terlihat pada saat guru memberikan pertanyaan, beberapa siswa tidak merespon guru.

Karakteristik utama kelas IVVI adalah siswa menampilkan perbedaan-perbedaan individual dalam banyak segi, diantaranya perbedaan dalam intelegensi, kemampuan dalam kognitif dan bahasa, perkembangan kepribadian dan perkembangan fisik anak. Dengan mengetahui karakteristik siswa tersebut guru melakukan pendekatanpendekatan yang berbeda kepada siswa yaitu dengan menerapkan disiplin belajar yang lebih tegas kepada siswa.

Disiplin belajar adalah kemampuan siswa dan kepatuhan siswa untuk mengendalikan diri secara sadar maupun suka rela untuk menghormati, menaati dan melaksanakan peraturan yang ditetapkan oleh diri sendiri maupun orang lain, peraturan tertulis maupun tidak tertulis dalam proses baik disiplin waktu maupun disiplin perbuatan.

$\begin{array}{rrr} & \text { Belajar merupakan suatu } \\ \text { proses usaha yang dilakukan }\end{array}$ seseorang untuk memperoleh suatu perubahan tingkah laku yang baru secara keseluruhan, sebagai hasil pengalamannya sendiri dalam interaksi dengan lingkungannya terhadap aspek pengetahuan, keterampilan dan sikap.

Hasil belajar adalah suatu keberhasilan yang dicapai dan kemampuan yang dimiliki oleh siswa setelah belajar, baik yang kognitif, afektif, psikomotorik, yang diwujudkan dalam bentuk angka yang diperoleh melalui tes yang diberikan kepada siswa setelah melalui proses pembelajaran.

Penerapan disiplin belajar di sekolah maupun di rumah akan mendorong, memotivasi, dan memaksa para siswa bersaing dalam belajar. Jadi, disiplin belajar di sekolah maupun di rumah 
Devi Efa Naibaho, Regina Sipayung, Darinda Sofia Tanjung : Hubungan Disiplin ...

menjadi faktor dominan dalam atau devenden variabel yang diberi mempengaruhi hasil belajar siswa. notasi huruf(Y)

Hasil belajar merupakan suatu keberhasilan yang dicapai dan kemampuan yang dimiliki siswa dalam bidang, kognitif,afektif dan kognitif.

\section{METODE PENELITIAN}

Rancangan atau Desain Penelitian

$$
\text { Variabel-variabel dalam }
$$

penelitian ini meliputi 2 variabel yaitu variabel terikat dan variabel bebas. Yang pertama adalah "disiplin belajar" yang diberi notasi huruf $\mathrm{X}$, sebagai variabel bebas, sedangkan variabel yang kedua adalah "hasil belajar" yang diposisikan sebagai variabel terikat

Populasi dan Sampel Penelitian Populasi Penelitian

Jika melakukan suatu penelitian harus memerlukan populasi. Sugiyono (2017: 117) mengatakan bahwa: "Populasi adalah wilayah generalisasi yang terdiri atas: obyek/subyek yang mempunyai kualiatas dan karakteristik tertentu yang ditetapkan oleh peneliti untuk dipelajari dan kemudian ditarik kesimpulannya". Menurut Margono (2010: 118) "Populasi adalah seluruh data yang menjadi perhatian kita dalam suatu ruang lingkup dan waktu kita tentukan".

Tabel 1. Data Populasi Siswa

\begin{tabular}{ccc}
\hline No & Kelas & Jumlah Siswa \\
1 & I & 18 \\
2 & II & 21 \\
3 & III & 27 \\
4 & IV & 25 \\
5 & V & 32 \\
6 & VI & 29 \\
& Total & 152 \\
\hline
\end{tabular}

Sampel Penelitian

Menurut Sugiyono (2017: 118) "Sampel adalah bagian dari jumlah dan karakteristik yang dimiliki oleh populasi tersebut". Dalam hal ini teknik sampel yang digunakan peneliti adalah Probability Sampling yaitu simple random sampling (sampel sederhana) artinya, setiap anggota dari populasi memiliki kesempatan dan peluang yang sama untuk dipilih sebagai sampel yang sistem pengambilannya secara acak. Ada pun sampel yang dijadikan peneliti adalah kelas V sebanyak 32 siswa.

Jenis dan Sumber Data

$$
\text { Sugiyono (2018: 193) }
$$

menyatakan pengumpulan data dapat menggunakan sumber primer dan sumber sekunder. Sumber primer adalah sumber data yang langsung 
memberikan data kepada pengumpul data, dan sumber sekunder merupakan sumber yang tidak langsung memberikan data kepada pengumpul data. Maka penelitian ini menggunakan sumber data primer yang di dapat langsung dari subjek peneliti.

Teknik dan Alat Pengumpulan Data

Pengumpulan data dilakukan dengan memberi kuesioner kepada siswa. Sebelum responden mengisi kuesioner, peneliti meminta responden untuk melihat arahan untuk mengisi kuesioner. Setelah itu, responden dipersilahkan mengisi kuesioner yang telah disediakan. Angket hubungan disiplin belajar dengan hasil belajar siswa dikumpulkan pada hari itu juga.

Kuesioner (Angket)

Menurut Sugiyono (2017: 199), kuesioner merupakan teknik pengumpulan data yang dilakukan dengan cara memberi seperangkat atau pernyataan tertulis kepada responden untuk dijawabnya.

Tabel 2. Kisi-kisi Instrumen Penelitian

\begin{tabular}{|c|c|c|c|c|c|c|}
\hline \multirow[t]{2}{*}{ Variabel } & \multirow{2}{*}{\multicolumn{2}{|c|}{ Indikator }} & \multirow{2}{*}{\multicolumn{2}{|c|}{ Sub Indikator }} & \multicolumn{2}{|c|}{ Nomor Soal } \\
\hline & & & & & Soal $(+)$ & Soal (-) \\
\hline \multirow[t]{8}{*}{$\begin{array}{l}\text { Disiplin } \\
\text { Belajar }\end{array}$} & 1. & $\begin{array}{l}\text { Menaati tata tertib } \\
\text { Sekolah }\end{array}$ & a. & $\begin{array}{l}\text { Disiplin siswa masuk } \\
\text { sekolah }\end{array}$ & $1,2,3$ & 4,5 \\
\hline & & & b. & $\begin{array}{l}\text { Disiplin siswa dalam } \\
\text { menaati tata tertib sekolah }\end{array}$ & 7,8 & 9,6 \\
\hline & 2. & $\begin{array}{l}\text { Perilaku } \\
\text { kedisiplinan }\end{array}$ & a. & $\begin{array}{l}\text { Mengikuti pelajaran di } \\
\text { sekolah }\end{array}$ & 11,12 & 13,14 \\
\hline & & di sekolah & & & & 10 \\
\hline & & & b. & $\begin{array}{l}\text { Disiplin dalam mengerjakan } \\
\text { tugas disekolah }\end{array}$ & $15,16,19,20$ & 17,18 \\
\hline & 3. & Disiplin dalam & a. & Tepat waktu dalam belajar & 27 & $28,29,30$ \\
\hline & & $\begin{array}{l}\text { menepati jadwal } \\
\text { belajar }\end{array}$ & b. & $\begin{array}{l}\text { Disiplin dalam mengerjakan } \\
\text { tugas sekolah/tugas rumah } \\
(\mathrm{PR})\end{array}$ & $23,24,25$ & 26 \\
\hline & 4. & $\begin{array}{l}\text { Belajar secara } \\
\text { teratur }\end{array}$ & a. & $\begin{array}{l}\text { Teratur dalam belajar dan } \\
\text { mengerjakan tugas. }\end{array}$ & $\begin{array}{c}31,35,36,37,3 \\
9,40\end{array}$ & $33,34,38,32$ \\
\hline
\end{tabular}

Dalam angket ini, disediakan lima jawaban dengan menggunakan skala likert. Menurut Sugiyono (2018: 93), skala Likert digunakan untuk mengukur sikap, pendapat, dan persepsi seseorang atau sekelompok orang tentang fenomena sosial. Dalam penelitian, fenomena sosial ini telah ditetapkan secara spesifik oleh peneliti, yang selanjutnya disebut sebagai variabel penelitian. Jawaban setiap item instrumen yang menggunakan skala likert mempunyai gradasi dari sangat positif sampai sangat negative, yang dapat berupa kata-kata antara lain: sangat setuju, setuju, ragu-ragu, tidak setuju, sangat tidak setuju. 
Devi Efa Naibaho, Regina Sipayung, Darinda Sofia Tanjung : Hubungan Disiplin ...

Tabel 3. Skor Alternatif Jawaban

\begin{tabular}{lcc}
\hline \multicolumn{1}{c}{ Alternative jawaban } & \multicolumn{2}{c}{ Skor Untuk Pernyataan } \\
Positif & Negative \\
Sangat Setuju & 5 & 1 \\
Setuju & 4 & 2 \\
Ragu-ragu & 3 & 3 \\
Tidak setuju & 2 & 4 \\
Sangat tidak setuju & 1 & 5 \\
\hline
\end{tabular}

\section{Studi Dokumentasi}

Dokumentasi merupakan suatu teknik pengumpulan data dengan menghimpun dan menganalisis dokumen tertulis maupun tidak tertulis, seperti arsip-arsip dan termasuk juga buku-buku tentang pendapat, teori yang berhubungan dengan masalah penelitian.

Uji Validitas Data dan Instrumen Uji Validitas

Sebelum instrumen dijadikan sebagai alat pengumpulan data maka instrumen ini perlu diperiksa apakah sudah valid dan reliabel. Uji validitas yang digunakan adalah dengan teknik analisis Product Moment dan person dengan bantuan analisis statistic SPSS 22. Adapun rumusnya sebagai berikut:

$$
r_{x y}=\frac{N \Sigma X Y-(\Sigma X)(\Sigma Y)}{\sqrt{\left\{N \Sigma X^{2}-(\Sigma X)^{2}\right\}\left\{N \Sigma Y^{2}-(\Sigma Y)^{2}\right\}}}
$$

(Arikunto, 2017: 87)

Keterangan:

$$
\begin{aligned}
r_{x y}= & \text { Koefisien korelasi antara } \\
& \text { variabel } \mathrm{X} \text { dan variabel } \mathrm{Y} \\
\mathrm{N} & =\text { Jumlah seluruh siswa } \\
\sum \mathrm{XY}= & \text { Jumlah hasil perkalian antara } \\
& \text { skor } \mathrm{X} \text { dan } \mathrm{Y} \\
\sum \mathrm{X}= & \text { Skor item } \\
\sum \mathrm{Y}= & \text { Skor total }
\end{aligned}
$$

Uji Reliabilitas

Menurut Siregar (2017: 87) reliabilitas bertujuan untuk mengetahui sejauh mana hasil pengukuran tetap konsisten, apabila dilakukan pengukuran dua kali atau lebih terhadap gejala yang sama dengan dengan menggunakan alat pengukur yang sama pula. Rumus reliabilitas menggunakan rumus Alpha menurut Arikunto (2018: 329 )adalah sebagai berikut:

$\mathrm{r}_{11}=\left(\frac{n}{n-1}\right)=\left\{1-\frac{\sum \sigma_{b}^{2}}{\sigma_{t}^{2}}\right\}$

Keterangan:

$\mathrm{r}_{11} \quad$ : Reliabilitas yang dicari

$\sum \sigma_{b}^{2} \quad$ Jumlah varians skor tiap-tiap item

$\sigma_{t}^{2} \quad$ : Varians total

$\mathrm{n}$ : Banyaknya butir pertanyaan

Uji Prasyarat Data

Uji Normalitas

Uji normalitas dilakukan untuk mengetahui apakah populasi berdistribusi normal apa tidak. Uji normalitas dilakukan dengan menggunakan uji Liliefoors, Sudjana (2017: 446-447). Rumus yang dipakai adalah rumus Liliefors, yaitu:

$Z i=\frac{\mathrm{Xi}-\mathrm{X}}{\mathrm{s}}$ 
Keterangan:

$\mathrm{X}=$ Rata-rata

$\mathrm{S}=$ Simpangan baku

Untuk mencari F Fitung

dilakukan dengan bantuan program SPSS versi 22.0. Rumus uji linearitas data adalah sebagai berikut:

$\mathrm{F}_{\text {reg }}=\frac{R K_{\text {reg }}}{R K_{\text {res }}}$

Keterangan :

$\mathrm{F}_{\text {reg }}=$ harga $\mathrm{F}$ untuk garis regresi

$\mathrm{RK}_{\text {reg }}=$ rerata kuadrat garis regresi

$\mathrm{RK}_{\text {res }}=$ rerata kuadrat garis residu

Uji Korelasi

Untuk mengetahui ada tidaknya pengaruh antara variabel bebas (X) dengan variabel terikat (Y), dengan rumus korelasi Product Moment yaitu:

$r_{x y}=\frac{N \sum X Y-\left(\sum X\right)\left(\sum Y\right)}{\sqrt{\left\{N \sum X^{2}-\left(\sum X\right)^{2},\left\{N \sum Y^{2}-\left(\sum Y\right)^{2}\right\}\right.}}$

(Sugiyono, 2018: 183)

Keterangan:

$\mathrm{r}_{\mathrm{xy}} \quad=$ Koefisien korelasi product moment

$\mathrm{N}=$ Jumlah seluruh siswa

$\sum \mathrm{X}=$ Skor item

$\sum \mathrm{Y}=$ Skor total seluruh siswa $\sum X Y=$ Jumlah hasil perkalian antara skor "X" dan skor "Y"

Uji Hipotesis

Untuk mengetahui apakah variabel $\mathrm{X}$ memiliki pengaruh yang signifikan terhadap variabel $Y$ dilakukan pengujian terhadap hipotesis dengan menggunakan uji $\mathrm{t}$ sebagai berikut:

$$
t=\frac{r \sqrt{n-2}}{\sqrt{1-r^{2}}}
$$

(Sugiyono, 2017: 187)

Keterangan:

$r=$ koefisien korelasi

$n=$ sampel

Jika $\mathrm{t}$ hitung $\geq \mathrm{t}$ tabel $:$ hipotesis alternatif diterima

Jika $\mathrm{t}$ hitung $\leq \mathrm{t}$ tabel : hipotesis alternatif ditolak

Uji Prasyarat Analisis

Uji Normalitas

Setelah dilakukan perhitungan dengan menggunakan SPSS Versi 22.0 pengujian normalitas yaitu dengan menggunakan uji Shapiro-Wilk, diketahui nilai signifikansi 0,05 .

Tabel 4. Uji Normalitas Instrumen

\begin{tabular}{|c|c|c|c|c|c|c|}
\hline \multicolumn{7}{|c|}{ Tests of Normality } \\
\hline & \multicolumn{3}{|c|}{ Kolmogorov-Smirnov ${ }^{\mathrm{a}}$} & \multicolumn{3}{|c|}{ Shapiro-Wilk } \\
\hline & Statistic & $\mathrm{df}$ & Sig. & Statistic & Df & Sig. \\
\hline $\begin{array}{l}\text { Disiplin } \\
\text { Belajar }\end{array}$ & .100 & 32 & $.200^{*}$ & .968 & 32 & .449 \\
\hline Hasil Belajar & .096 & 32 & $.200^{*}$ & .978 & 32 & .746 \\
\hline $\begin{array}{l}* \text { This is a lo } \\
\text { a. Lilliefors } \mathrm{S}\end{array}$ & $\begin{array}{l}\text { bound of } \\
\text { ificance } \mathrm{C}\end{array}$ & $\begin{array}{l}\text { true sigr } \\
\text { ction }\end{array}$ & cance. & & & \\
\hline
\end{tabular}


Devi Efa Naibaho, Regina Sipayung, Darinda Sofia Tanjung : Hubungan Disiplin ...

Uji Linieritas

Hasil perhitungan uji linieritas

pada variabel bebas dengan variabel terikat pada penelitian ini adalah sebagai berikut:

Tabel 5. Uji Linearitas

\begin{tabular}{|c|c|c|c|c|c|c|c|}
\hline \multicolumn{8}{|c|}{ ANOVA Table } \\
\hline \multirow{6}{*}{$\begin{array}{l}\text { Hasil Belajar * } \\
\text { Disiplin Belajar }\end{array}$} & \multirow{4}{*}{$\begin{array}{l}\text { Between } \\
\text { Groups }\end{array}$} & \multirow[b]{2}{*}{ (Combined) } & \multirow{2}{*}{$\begin{array}{l}\text { Sum of } \\
\text { Squares } \\
1449.552\end{array}$} & & \multirow{2}{*}{$\begin{array}{l}\text { Mean } \\
\text { Square } \\
69.026\end{array}$} & \multirow{2}{*}{$\begin{array}{c}\mathrm{F} \\
5.817\end{array}$} & \multirow{2}{*}{$\begin{array}{l}\text { Sig. } \\
.003\end{array}$} \\
\hline & & & & & & & \\
\hline & & Linearity & 887.113 & 1 & 887.113 & 74.757 & .000 \\
\hline & & $\begin{array}{l}\text { Deviation } \\
\text { from Linearity }\end{array}$ & 562.439 & 20 & 28.122 & 2.370 & .081 \\
\hline & Within $\mathrm{G}_{1}$ & & 118.667 & 10 & 11.867 & & \\
\hline & Total & & 1568.219 & 31 & & & \\
\hline
\end{tabular}

\section{Uji Korelasi}

Analisis korelasi dengan menggunakan rumus $r_{x y}$ bertujuan untuk membuktikan adanya pengaruh yang signifikan antara variabel $\mathrm{x}$ dengan variabel y.

\section{Tabel 6. Hasil Uji Korelasi}

\begin{tabular}{llrr}
\hline & & \\
& & & \\
\multirow{2}{*}{ Disiplin Belajar } & Disiplin Belajar & Hasil Belajar \\
& Pearson Correlation & 1 & $.752^{* *}$ \\
& Sig. (2-tailed) & & .000 \\
Hasil Belajar & $\mathrm{N}$ & 32 & 32 \\
& Pearson Correlation & $.752^{* *}$ & 1 \\
& Sig. (2-tailed) & .000 & 32 \\
$* *$. Correlation is significant at the 0.01 level (2-tailed). & & \\
\hline
\end{tabular}

\section{Uji Hipotesis Penelitian}

Pengujian hipotesis pada penelitian ini dilakukan dengan menggunakan uji t dengan berbantuan program SPSS ver 22.0. Uji $\mathrm{t}$ digunakan untuk mengetahui ada tidaknya hubungan variabel bebas terhadap variabel terikat yaitu variabel disiplin belajar dengan hasil belajar. Pengujian hipotesis dengan menggunakan uji t dilakukan dengan cara membandingkan thitung dengan $\mathrm{t}_{\text {tabel. }}$ Kriteria pengujian dengan menggunakan uji $\mathrm{t}$ adalah jika $\mathrm{t}_{\text {hitung }} \geq$ $t_{\text {tabel }}$ hipotesis alternatif diterima dan jika $t_{\text {hitung }} \leq \mathrm{t}_{\text {tabel }}$ hipotesis alternatif ditolak. Berikut akan disajikan tabel dari hasil pengujian hipotesis dengan berbantuan program SPSS ver 22.0. 
Tabel 7. Uji Hipotesis

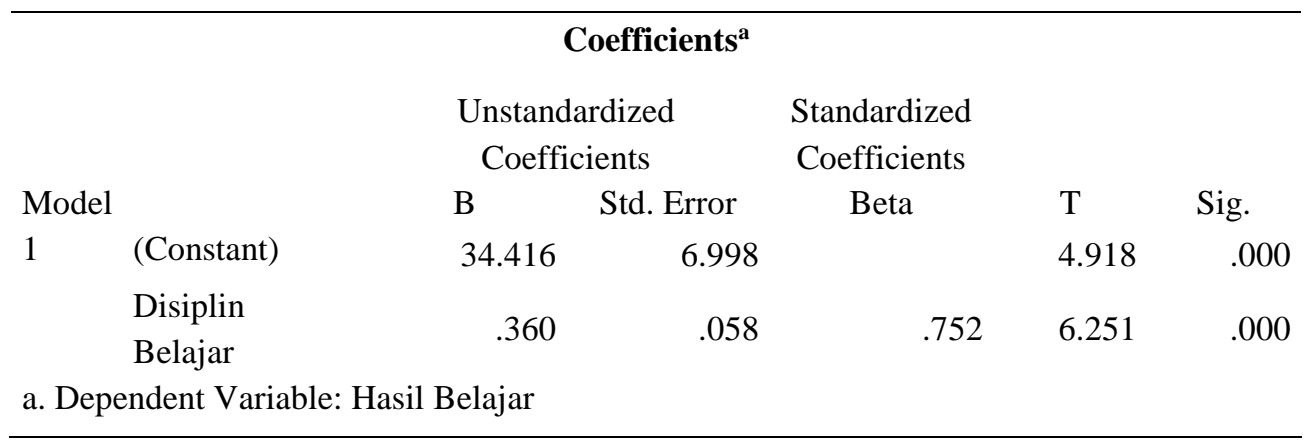

\section{Pembahasan}

Dari hasil pengolahan data diperoleh nilai signifikansi disiplin belajar adalah $0,449 \leq 0,930$ hasil belajar siswa signifikannya $0,746 \leq$ 0,930 . Berdasarkan hasil perhitungan tersebut dapat diketahui bahwa nilai signifikansi dari disiplin belajar dan hasil belajar siswa lebih besar dari 0,05 , dapat disimpulkan bahwa data disiplin belajar dan hasil belajar siswa berdistribusi normal.

Uji linieritas antara variabel bebas disiplin belajar dengan variabel terikat hasil belajar siswa dapat dilihat dari nilai sig. Deviation from Linearity, berdasarkan hasil perhitungan diperoleh nilai sig. Deviation from Linearity sebesar 0,081. Nilai sig. Deviation from Linearity lebih besar dari 0,05 maka dapat disimpulkan bahwa hubungan antara disiplin belajar dengan hasil belajar siswa bersifat linier.

Hasil penelitian ini menunjukkan bahwa disiplin belajar memiliki hubungan dengan hasil belajar siswa. Hal tersebut terbukti dari nilai $r_{x y} 0,752$. Berdasarkan tabel interpretasi nilai $r$, korelasi $r_{x y} 0,752$ terletak pada rentang nilai $r$ 0,6000,800 maka, dapat disimpulkan tingkat hubungan antara variabel disiplin belajar dengan hasil belajar siswa memiliki hubungan tinggi.

Disiplin belajar adalah kemampuan siswa dan kepatuhan siswa untuk mengendalikan diri secara sadar maupun suka rela untuk menghormati, menaati, dan melaksanakan peraturan yang ditetapkan oleh diri sendiri maupun orang lain, peraturan tertulis maupun tidak tertulis dalam proses baik disiplin waktu maupun disiplin perbuatan. Berdasarkan hasil penelitian ini menunjukkan bahwa disiplin belajar memiliki hubungan yang positif dan signifikan, hal tersebut terbukti dari nilai $t_{\text {hitung }} \geq t_{\text {tabel }}$ sebesar $6,251 \geq 1,697$. Maka dengan demikian $\mathrm{H}_{\mathrm{o}}$ diterima yaitu ada hubungan yang signifikan antar disiplin belajar (X) dengan hasil belajar siswa (Y). 
Devi Efa Naibaho, Regina Sipayung, Darinda Sofia Tanjung : Hubungan Disiplin ...

\section{SIMPULAN}

Dari hasil penelitian yang telah dilakukan, dapat disimpulkan sebagai berikut: Hasil perhitungan uji normalitas disiplin belajar dan hasil belajar diperoleh nilai signifikansi disiplin belajar adalah 0,449 dan hasil belajar 0,749. Hasil perhitungan uji linearitas diperoleh nilai sig. Deviation from Linearity sebesar 0,081 . Hasil uji perhitungan korelasi diperoleh $\mathrm{r}_{\mathrm{xy}} 0,75$. Hasil uji hipotesis diperoleh $t_{\text {hitung }}$ sebesar 6,251 lebih besar dari $t_{\text {tabel }} 1,697$ sehingga dapat diartikan regresi antara variabel terikat disiplin belajar (x) dengan variabel bebas (y) mempunyai hubungan positif dan signifikan. Sehingga perhitungan tersebut berarti hipotesis kerja (Ho) diterima yaitu "Ada hubungan yang signifikan antara disiplin belajar dengan hasil belajar siswa kelas V SD Negeri 24 Tanjung Bunga.

\section{DAFTAR RUJUKAN}

Alimaun, Iman. 2015. Pengaruh Kedisiplinan Terhadap Hasil Belajar Siswa Kelas V Sekolah Dasar Se-Daerah Binaan R.A Kartini Kecamatan Kutoarjo Kabupaten Purwarejo. Semarang: Skripsi, Universitas Semarang.

Amri, Sofan. 2016. Pengembangan \& Model Pembelajaran dalam Kurikulum 2013. Jakarta: Prestasi Pustaka Publisher. Awaluddin., Dkk. 2017. Hubungan Antara Penanaman Nilai Kedisiplinan Terhadap Hasil Belajar Pkn Pada Siswa Kelas
IV Di SD Negeri 1 Pagar Air Kabupaten Aceh Besar. Jurnal Ilmiah Pendidikan Guru Sekolah Dasar.Vol 2 No 1.

Arikunto, Suharsimi. 2017. Prosedur Penelitian. Jakarta: Rineka Cipta.

Arikunto, Suharsimi. 2018. Prosedur Penelitian Suatu Pendekatan Praktik. Jakarta: Rineka Cipta.

Djamarah. 2018. Psikologi Belajar. Jakarta: Rineka Cipta.

Istirani dan Pulungan. 2018. Ensiklopedia Pendidikan. Medan: Media Persada.

Jihad, Asep dan Abdul Haris. 2018. Evaluasi Pembelajaran. Yogyakarta: Muti Pressindo.

Khairani, Makmun. 2017. Psikologi Belajar. Yogyarta: Aswaja Pressindo.

Margono. 2010. Metodologi Penelitian Pendidikan. Jakarta: Rineka Cipta.

Noor. 2017. Metodologi Penelitian. Jakarta: Kencana

Rosyid, Dkk. 2019. Prestasi Belajar. Malang: Literasi Nusantara.

Rusman. 2017. Belajar dan Pembelajaran. Jakarta: Kencana.

Sardiman, 2014. Belajar dan Pembelajaran. Jakarta: Rineka Cipta.

Silaban, P. J. 2015. Meningkatkan Motivasi dan Kemanpuan Pemahaman Matematis Siswa Melalui Pembelajaran Kooperatif Tipe TGT Berbantuan Alat Peraga Pada Mata Pelajaran Matematika di Kelas VI SD Methodist 12 
Medan. Jurnal Ilmiah MBP:

Vol. 3 No. 2.

Sipayung, Regina. 2018. Pengaruh

Pola Asuh Orangtua dan

Disiplin Belajar Terhadap

Hasil Belajar Siswa SD Kelas V

di SD Negeri Muara Bolak 4

Kec.Sosorgadong. Jurnal

Ilmiah Maksitek: Vol. 3 No. 4.

Slameto. 2017. Belajar dan Faktor-

faktor yang Mempengaruhi.

Jakarta: Rineka Cipta.

Sugiyono. 2015. Statistika Untuk

Penelitian. Bandung: Alfabeta.

Sugiyono. 2018. Statistika Untuk

Penelitian. Bandung: Alfabeta.

Suhrawardi, Dkk. 2019. Hubungan

Antara Konsep Diri Dengan

Disiplin Siswa Kelas V di SDN

Kota Batu 02 Kecamatan

Ciomas Kabupaten Bogor

Semester Ganjil Tahun

Pembelajaran 2018/2019.

Jurnal Pendidikan \&

Pengajaran Guru Sekolah

Dasar. Vol 02 No 01

Susanti, Lidia. 2019. Prestasi Belajar Akademik dan Non Akademik.

Malang: Prenada Media Group.

Susanto, Ahmad. 2018. Teori Belajar dan Pembelajaran di Sekolah Dasar. Jakarta: Prenada Media Group.

Suyono dan Hariyanto. 2016. Belajar dan Pembelajaran. Bandung: Remaja Rosdakarya. 